\title{
The Association of EHR Drug Safety Alerts and Co-prescribing of Opioids and Benzodiazepines
}

\author{
Laura Barrie Smith, $B A^{7}$, Ezra Golberstein, $P h D^{7}$, Kelly Anderson, RN, $B S N^{2}$, \\ Tori Christiaansen, $\mathrm{MD}^{2}$, Nicole Paterson, PharmD BCPS ${ }^{2}$, Sonja Short, MD' ${ }^{2}$, and Hannah T. Neprash, PhD ${ }^{1}$
}

'Division of Health Policy \& Management, School of Public Health, University of Minnesota, Minneapolis, MN, USA; '²airview Health Services, Minneapolis, MN, USA.

$\mathrm{J}$ Gen Intern Med 34(8): 1403-5

DOI: $10.1007 / \mathrm{s} 11606-019-04985-w$

(C) Society of General Internal Medicine 2019

\section{BACKGROUND}

Concurrent opioid and benzodiazepine use is associated with an increased risk of overdose, compared with opioid users who do not use benzodiazepines. ${ }^{1,2}$ Reflecting this safety concern, the Center for Disease Control and Prevention's 2016 chronic pain guideline recommended against coprescribing opioids and benzodiazepines. ${ }^{3}$ Nevertheless, clinicians frequently co-prescribe these medications. A recent estimate finds that $17 \%$ of opioid users concurrently use a benzodiazepine. ${ }^{1}$

\section{OBJECTIVE}

To determine the percentage of visits resulting in an opioid prescription for a patient with an active benzodiazepine prescription, and vice versa, before and after the implementation of an electronic health record (EHR) alert notifying clinicians at the time of prescribing of the dangers of concurrent opioid and benzodiazepine use.

\section{METHODS AND FINDINGS}

We conducted a retrospective analysis using EHR data from all office and outpatient clinic visits occurring between April 2017 and April 2018 at Fairview Health Systems, a large integrated delivery system in the greater Minneapolis-St. Paul metropolitan area. On October 11, 2017, Fairview initiated an EHR alert designed to deter concurrent prescribing of opioids and benzodiazepines in office settings. Upon initiation of an opioid order, the alert notified clinicians of overlap with an active benzodiazepine prescription, and vice versa; warned of the safety risk, and recommended ordering Naloxone. The clinician could easily dismiss the alert without changing or justifying the prescription order.

We created two analytic samples of office visits with patients at risk for co-prescribing: those with an active opioid prescription at the time of visit (observed in the patient's

Published online April 22, 2019 medication history) and those with an active benzodiazepine prescription. Our outcome of interest was an indicator for benzodiazepine prescribing and opioid prescribing in the visit, respectively. We used interrupted time series linear regression models to estimate the probability of co-prescribing in each sample before and after the intervention began. We assessed changes in the probability of co-prescribing, testing for a change in level at the time of the intervention and a change in trend. Regression models controlled for patient characteristics (age, sex, race/ethnicity, history of chronic pain, history of substance use disorder) and clinician characteristics (clinician type and department). Analyses were conducted using SAS 9.4 and Stata 13.1. The study was approved by the University of Minnesota IRB.

We identified 211,323 office visits for patients with a current opioid prescription and 85,817 office visits for patients with a current benzodiazepine prescription. The characteristics of the samples are described in the Table 1. Figure 1 shows the unadjusted trends in prescribing, along with the results of the regression models. We observed no significant change in the level of benzodiazepine prescribing immediately following the intervention $(p=0.56)$, and the adjusted trend in benzodiazepine prescribing decreased after the intervention $(p=0.02)$. There was no statistically significant change in the level of opioid prescribing $(p=0.24)$ or in the trend in opioid prescribing after the intervention $(p=0.80)$.

\section{DISCUSSION}

We find that the introduction of an EHR alert designed to deter co-prescribing of opioids and benzodiazepines in an outpatient setting had little to no effect on the co-prescribing decisions of clinicians within a large integrated delivery system. This result may reflect that clinicians considered co-prescribing clinically appropriate and beneficial, even after receiving safety information. However, other research finds that physicians frequently override clinical decision support alerts related to opioids, suggesting that clinicians may suffer from EHR alert fatigue. ${ }^{4}$

One advantage of using EHR data is the ability to observe medication orders along with detailed diagnosis information recorded during the associated visit. However, our analysis has limitations. Our ability to identify concurrent opioid and 
Table 1 Sample Characteristics

\begin{tabular}{|c|c|c|c|c|c|c|c|c|c|c|c|c|c|c|}
\hline \multirow{5}{*}{$\begin{array}{l}\text { Patient age in } \\
\text { years, mean } \\
\text { (SD) } \\
\text { Female, no. } \\
(\%)\end{array}$} & \multicolumn{7}{|c|}{ Appointments with current opioid } & \multicolumn{7}{|c|}{ Appointments with current benzodiazepine } \\
\hline & \multicolumn{7}{|c|}{ (Total $N=211,323$ ) } & \multicolumn{7}{|c|}{ (Total $N=\mathbf{8 5 , 8 1 7}$ ) } \\
\hline & \multicolumn{2}{|l|}{ Total } & \multicolumn{2}{|c|}{$\begin{array}{l}\text { Did not receive } \\
\text { benzodiazepine } \\
(N=\mathbf{2 0 6}, 127)\end{array}$} & \multicolumn{2}{|c|}{$\begin{array}{l}\text { Received } \\
\text { benzodiazepine } \\
(N=5196)\end{array}$} & \multirow{2}{*}{$\begin{array}{l}\boldsymbol{P} \\
\text { value* }^{*}\end{array}$} & \multicolumn{2}{|l|}{ Total } & \multicolumn{2}{|c|}{$\begin{array}{l}\text { Did not } \\
\text { receive opioid } \\
(N=77,408)\end{array}$} & \multicolumn{2}{|c|}{$\begin{array}{l}\text { Received opioid } \\
(N=8409)\end{array}$} & \multirow{2}{*}{$\begin{array}{l}\boldsymbol{P} \\
\text { value* } \\
0.00\end{array}$} \\
\hline & 55 & $(17.58)$ & 55.36 & $(17.63)$ & 52.29 & $(14.74)$ & & 53 & $(17.12)$ & 53.50 & $(17.41)$ & 52.54 & $(14.31)$ & \\
\hline & 124,901 & (59) & 121,362 & (59) & 3533 & $(68)$ & 0.00 & 58,093 & $(68)$ & 52,327 & $(68)$ & 5766 & (69) & 0.07 \\
\hline \multicolumn{15}{|l|}{ Race/ethnicity: } \\
\hline White & 185,810 & $(88)$ & 181,122 & $(88)$ & 4688 & $(90)$ & 0.00 & 79,825 & $(93)$ & 72,250 & (93) & 7575 & $(90)$ & 0.00 \\
\hline Black & 15,963 & (8) & 15,629 & (8) & 334 & (6) & 0.00 & 3345 & (4) & 2794 & (4) & 551 & (7) & 0.00 \\
\hline Asian & 4266 & (2) & 4224 & (2) & 42 & (1) & 0.00 & 1056 & (1) & 981 & (1) & 75 & (1) & 0.00 \\
\hline $\begin{array}{l}\text { Hispanic } \\
\text { or Latino }\end{array}$ & 3058 & (1) & 3010 & (1) & 48 & (1) & 0.00 & 879 & (1) & 789 & (1) & 90 & (1) & 0.66 \\
\hline Other & 2226 & (1) & 2142 & (1) & 84 & (2) & 0.00 & 712 & (1) & 594 & (1) & 118 & (1) & 0.00 \\
\hline $\begin{array}{l}\text { History of } \\
\text { substance use } \\
\text { disorder** }\end{array}$ & 34,559 & (16) & 33,276 & (16) & 1283 & (25) & 0.00 & 12,289 & (14) & 9914 & (12) & 2375 & (28) & 0.00 \\
\hline $\begin{array}{l}\text { History of pain } \\
\text { diagnoses }\end{array}$ & 121,888 & $(58)$ & 117,987 & (57) & 3901 & $(75)$ & 0.00 & 42,449 & $(49)$ & 35,481 & (46) & 6968 & $(83)$ & 0.00 \\
\hline \multicolumn{15}{|l|}{ Clinician type } \\
\hline Physician & 158,560 & $(75)$ & 154,923 & (75) & 3637 & $(70)$ & 0.00 & 61,434 & $(72)$ & 55,346 & (72) & 6088 & (72) & 0.08 \\
\hline $\begin{array}{l}\text { Nurse } \\
\text { practitioner }\end{array}$ & 26,896 & (13) & 26,081 & (13) & 815 & (16) & 0.00 & 12,670 & (15) & 11,459 & (15) & 1211 & (14) & 0.32 \\
\hline $\begin{array}{l}\text { Physician } \\
\text { assistant }\end{array}$ & 25,867 & (12) & 25,123 & (12) & 744 & (14) & 0.00 & 11,713 & (14) & 10,603 & (14) & 1110 & (14) & 0.21 \\
\hline \multicolumn{15}{|l|}{$\begin{array}{l}\text { Department } \\
\text { type }\end{array}$} \\
\hline $\begin{array}{l}\text { Family or } \\
\text { internal } \\
\text { medicine }\end{array}$ & 112,840 & (53) & 102,974 & $(50)$ & 4377 & (84) & 0.00 & 52,689 & (61) & 46,136 & $(60)$ & 6553 & (78) & 0.00 \\
\hline Surgical & 26,300 & (12) & 26,201 & (13) & 99 & (2) & 0.00 & 5076 & (6) & 4774 & (6) & 302 & (4) & 0.00 \\
\hline $\begin{array}{l}\text { Other/ } \\
\text { specialty }\end{array}$ & 72,183 & $(34)$ & 76,952 & (37) & 720 & (14) & 0.00 & 28,052 & $(33)$ & 26,498 & (34) & 1554 & (18) & 0.00 \\
\hline
\end{tabular}

*P values come from two-sided $t$ tests for a difference in means

$* *$ Patients are considered to have a history of substance use disorder/pain if any ICD-10 diagnoses for substance use disorder/pain appear in their EHR records in the past 6 months

benzodiazepine use relies on the start and end date of medi-

whether the patient fills a prescription, takes the medication as cations prescribed by Fairview providers. We cannot observe

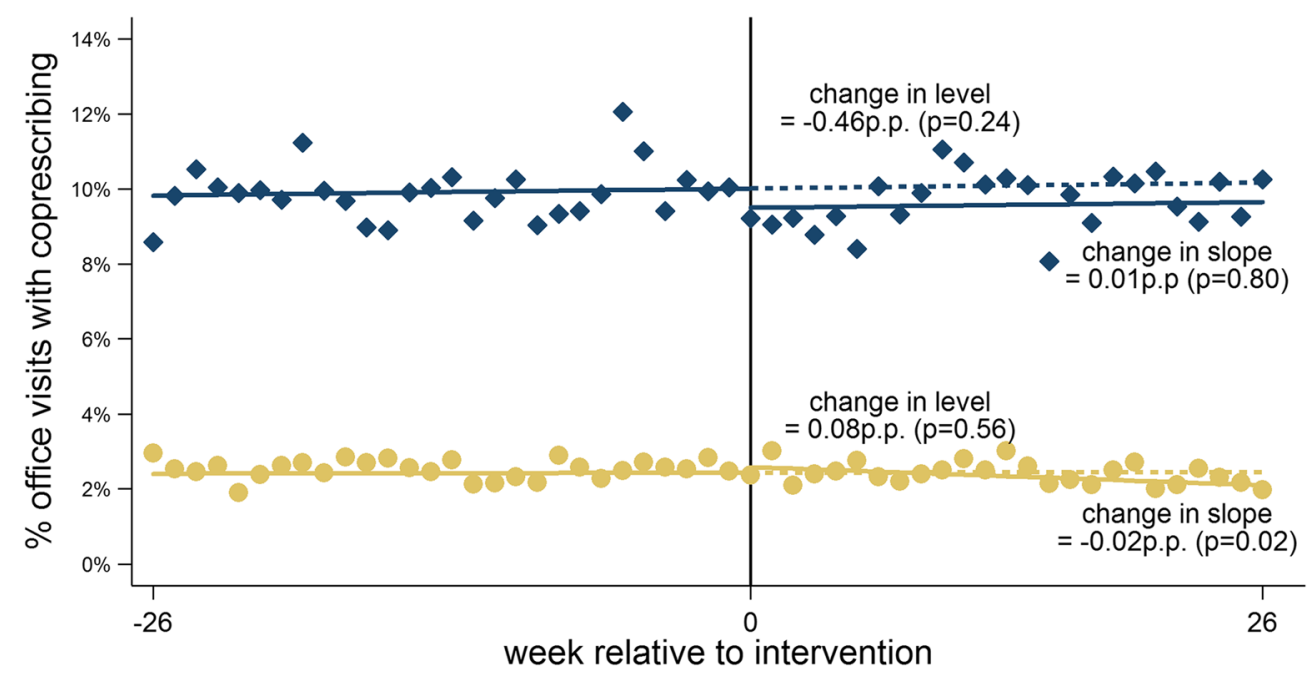

Fig. 1 Interrupted time series regression results: opioid and benzodiazepine co-prescribing by week $>$ opioids, observed, - opioids, adjusted time trend, - - opioids, extension of pre-trend, benzodiazepines, observed, - benzodiazepines, adjusted time trend, =- benzodiazepines, extension of pre-trend. 
As EHRs become increasingly widespread in clinical practices, clinical decision support tools within the EHR are increasingly deployed to steer providers toward higher quality care. Recent efforts to curb potential over-prescribing of controlled substances have used the EHR to deliver clinical decision support at the time of prescribing. ${ }^{5}$ EHR-based interventions that go beyond provision of safety information - whether by setting a small default prescription quantity or by requiring that a clinician justify a particular prescribing decision-may prove more successful in encouraging appropriate prescribing.

Acknowledgements: This research was supported by the National Institutes of Health's National Center for Advancing Translational Sciences (Grant No. UL1TR002494) and the Agency for Healthcare Research and Quality T32 trainee program (Smith). The content is solely the responsibility of the authors and does not necessarily represent the official views of the National Institutes of Health's National Center for Advancing Translational Sciences nor the Agency for Healthcare Research and Quality.

Corresponding Author: Hannah T. Neprash, PhD; Division of Health Policy \& Management, School of Public Health University of Minnesota, Minneapolis, MN, USA (e-mail: hneprash@umn.edu).

\section{Compliance with Ethical Standards:}

The study was approved by the University of Minnesota IRB.
Conflict of Interest: Ms. Smith reports no conflict of interest. Dr. Golberstein reports no conflict of interest.

Ms. Anderson reports no conflict of interest.

Dr. Christiaansen reports no conflict of interest.

Dr. Paterson reports no conflict of interest.

Dr. Short reports no conflict of interest.

Dr. Neprash reports receiving consulting compensation from athenahealth, Inc.

\section{REFERENCES}

1. Sun EC, Dixit A, Humphreys K, Darnall BD, Baker LC, Mackey S. Association between concurrent use of prescription opioids and benzodiazepines and overdose: retrospective analysis. BMJ 2017;356:j760.

2. Hernandez I, He M, Brooks MM, Zhang Y. Exposure-Response Association Between Concurrent Opioid and Benzodiazepine Use and Risk of Opioid-Related Overdose in Medicare Part D Beneficiaries. JAMA Netw Open 2018;1(2):e180919.

3. Dowell D, Haegerich TM, Chou R. CDC Guideline for Prescribing Opioids for Chronic Pain-United States, 2016. JAMA 2016;315(15):1624.

4. Genco EK, Forster JE, Flaten $\mathbf{H}$, et al. Clinically Inconsequential Alerts: The Characteristics of Opioid Drug Alerts and Their Utility in Preventing Adverse Drug Events in the Emergency Department. Ann Emerg Med 2016;67(2):240-248.e3.

5. Ballo J, Boczenowski MLSS, Mccready BSRG, et al. Pain Management Resources to Support Clinical Decision Support Artifact Development: An Environmental Scan. Agency for Healthcare Research and Quality; 2017.

Publisher's Note Springer Nature remains neutral with regard to jurisdictional claims in published maps and institutional affiliations. 